University of Nebraska - Lincoln

DigitalCommons@University of Nebraska - Lincoln

Faculty Publications: Department of Teaching, Department of Teaching, Learning and Teacher Learning and Teacher Education

Education

2010

\title{
A Call for a New Geoscience Education Research Agenda
}

Elizabeth B. Lewis

University of Nebraska-Lincoln, elewis3@unl.edu

Dale R. Baker

Arizona State University, DALE.BAKER@asu.edu

Follow this and additional works at: https://digitalcommons.unl.edu/teachlearnfacpub

Part of the Teacher Education and Professional Development Commons

Lewis, Elizabeth B. and Baker, Dale R., "A Call for a New Geoscience Education Research Agenda" (2010). Faculty Publications: Department of Teaching, Learning and Teacher Education. 122.

https://digitalcommons.unl.edu/teachlearnfacpub/122

This Article is brought to you for free and open access by the Department of Teaching, Learning and Teacher Education at DigitalCommons@University of Nebraska - Lincoln. It has been accepted for inclusion in Faculty Publications: Department of Teaching, Learning and Teacher Education by an authorized administrator of DigitalCommons@University of Nebraska - Lincoln. 
Published in Journal of Research in Science Teaching 47:2 (2010), pp. 121-129; doi: 10.1002/tea.20320

Copyright (C) 2009 Wiley Periodicals, Inc. Used by permission.

Submitted October 3, 2008; accepted May 21, 2009; published online November 25, 2009.

\title{
A Call for a New Geoscience Education Research Agenda
}

\author{
Elizabeth B. Lewis \\ Department of Teaching, Learning, and Teacher Education, \\ Henzlik Hall, College of Education and Human Sciences, \\ University of Nebraska-Lincoln, Lincoln, Nebraska 68588 \\ Dale R. Baker \\ Mary Lou Fulton College of Education, \\ Arizona State University, Tempe, Arizona \\ Corresponding author - E. B. Lewis, email elewis3@unl.edu
}

\begin{abstract}
A lack of qualified teachers and low enrollment in the geosciences exist at both secondary and tertiary levels in the United States. Consequently, it is unlikely that students will be able to achieve scientific literacy without an increase in both of these populations. To address these problems, we pose research questions, highlight sociocultural theories, and provide examples of other science education research as possible avenues by which to explore these related problems. We argue that such research studies are necessary to inform science education policy and advance national scientific literacy.
\end{abstract}

Keywords: geoscience education, Earth and space science teacher education, undergraduate enrollment, scientific literacy, sociocultural research

\section{Geoscience Education: Marginalized or Poised for a Breakthrough?}

Over the last half century, the geosciences have struggled to gain an equal footing in K-12 education with life and physical science (Dodick \& Orion, 2003; Ridky, 2002). Earth and space science (ESS) is not central to the high school curriculum; only $7 \%$ of high school students nationally take such courses. These enrollment figures are at odds with the National Science Education Standards (NSES) (NRC, 1996) that give equal emphasis to ESS as part of a national vision of scientific literacy and underscore the nature of the problem facing geoscience educators.

In 2001, representatives from all areas and levels of the geosciences engaged in a national conference on the state of geoscience education. They developed major, long-term recommendations and a vision for improving the state of geoscience education, which are presented in the Blueprint for Change: Report from the National Conference on the Revolution on Earth and Space Science Education (Barstow \& Geary, 2002). These recommendations reinforce and elaborate upon the Benchmarks for Scientific Literacy (AAAS, 1993) and the NSES (NRC, 1996), providing an academic agenda for geoscience educators and a call to action. The report recommendations include offering ESS as a lab course at the high school level, establishing state-based alliances to promote ESS education reform, and developing a strong research program in ESS education.

We believe that building a new research agenda for geoscience education upon the broad research base in science education and the research produced in other scientific domains can productively address the challenges facing geoscience education. We advocate multiple approaches to examine the problems of geoscience education for two reasons. The first is that if there is continued marginalization of K-12 ESS education, we will never achieve the vision of scientific literacy as defined by the NSES in the United States. The second is that impoverished geoscience literacy (Mayer, 2002) among American citizens ensures a lack of understanding of environmental issues, disaster preparedness, and prudent resource use. 
In this editorial we pose research questions, as well as possible models as avenues by which to explore the dual problems of geoscience education and production of ESS teachers. This editorial's main purpose is to stimulate inquiry into geoscience education because we currently do not have a critical mass of data to translate into sound recommendations. To support this assertion, we reviewed the last 7 years of articles in the Journal of Research in Science Teaching. As expected, we did not find any studies that directly related to the issue of advancing geoscience education as part of scientific literacy, the problem of low K-16 student enrollment and class offerings, or the national supply of geoscience teachers. We did find one recent study in JRST by Britner (2008) on the motivation of high school science students and gender differences in life, physical, and Earth science classes. Britner found that high school girls earned higher grades in Earth science classes and reported stronger self-efficacy than boys. The girls in this study also reported higher grades, but lower self-efficacy and higher science anxiety, in their life science and physical science classes. Despite a shortage of research articles specifically about the geosciences in JRST, we did find many excellent examples of sociocultural research that could provide fruitful frameworks for future research in the geosciences. A sociocultural perspective helps us describe both the phenomena and increase our understanding of the relationship among multiple interacting factors that may lead to data-supported actions in the geosciences.

\section{Challenges Facing Geoscience Education}

Problems in geoscience education in the United States exist at both the tertiary and secondary level. In higher education today, geology departments are producing $65 \%$ fewer undergraduate geoscience majors than they did in the early 1980s, and 50\% less than in the mid-1990s (American Geological Institute data reported in Ridky, 2002). In secondary education we lack enough highly qualified ESS teachers to fill current needs and expand teacher ranks. We also fail to provide equitable and uniform student access to geoscience education.

\section{Undergraduate Majors in Science}

The number of students majoring in the biological sciences is large. Biology departments are graduating greater numbers of biology majors each year, and women majors $(39,913=62 \%)$ now exceed men $(23,979=38 \%)(\mathrm{NSF}, 2007)$. In contrast, the number of undergraduate majors in the geosciences is small. And, even though the number of women has increased, men $(1,812=57 \%)$ still outnumber women $(1,358$ $=43 \%$ ) (NSF, 2007). In addition, geoscience departments have had difficulty attracting and retaining students from underrepresented groups, who comprise only $6.3 \%$ of undergraduate majors nationally (Huntoon \& Lane, 2007). This is well below the percentage of minority students in the general K-16 population and is one of our greatest equity challenges.

\section{Secondary Science Teacher Supply}

Only 19\% of all 8th grade ESS teachers have undergraduate majors in geoscience, $39 \%$ have other science majors, $21 \%$ are elementary certified, and $21 \%$ are not certified at all (NAEP, 2000). Fifteen percent of all high school science teachers are assigned to teach one or more sections of ESS, and of those teachers, $72 \%$ are certified to teach ESS and have a major or a minor concentration in the field (Blank \& Langesen, 2005). Earth science classes are more likely to be taught by out-of-field teachers than are other sciences and only 39\% of secondary earth science classes are taught by teachers who have had at least six semesters of college coursework in geoscience. An additional 21\% of ESS classes are taught by teachers who have had in-depth coursework in another science discipline, while $40 \%$ of secondary earth science classes are taught by teachers without any in-depth preparation in science (Horizon Research, Inc., 2002a). In comparison, $68 \%$ of secondary physics and physical science classes and $82 \%$ of secondary life science classes are taught by teachers with six or more semesters in those domains of science (Horizon Research, Inc., 2002a).

In 1966, the Earth Science Curriculum Project staff predicted that there would be a need for 20,000 teachers by 1970; at the time there were only about 6,000-7,000 "more or less qualified earth science teachers" (Romey, 1966, p. 89). Forty years later, with about 15,600 teachers, we still have not reached the numbers needed in 1970 to teach geoscience (Lewis, 2008). This persistent lack of teachers is further exacerbated by large numbers of ESS teachers retiring, estimated at about 30\% by 2010 (Horizon Research, Inc., 
2002a). In reality the number of ESS teachers may be inflated. Horizon Research, Inc.'s (2002a) tally was done 7 years ago and by using their estimation of ESS teacher retirement rate as we rapidly approach the year 2010 milestone, we may soon be looking at a corps of: $15,600-(0.30 \times 15,600)=10,920+X$, where $X$ $=$ an unknown number of newly certified ESS teachers. If $88 \%$ of high school students take biology and we need over 52,000 teachers to teach them, it follows that with only about 15,600 ESS teachers we do not have enough highly qualified teachers to meet the need for the equivalent percentage of students. Furthermore, the supply of ESS teachers is not uniform across the United States. Some states have more robust ESS teacher education programs and commensurately higher demands for Earth science teachers (e.g., New York). As such, there can be no one standardized approach in solving this national problem.

\section{Women Science Teachers}

Since 1977, the number of women secondary science teachers has steadily increased. They now comprise about $52 \%$ of all secondary science teachers. Half of grades 6-12 ESS teachers are women (Horizon Research, Inc., 2002b). In high school biology 52\% $(27,402)$ of teachers are women, and in chemistry $47 \%$ $(13,135)$. In contrast, only 30\% $(5,890)$ of physics teachers are women (CCSSO, 2005). A survey of American teachers conducted by the National Education Association (NEA, 2003) indicated that the numbers of men teaching at the secondary level decreased from $57 \%$ in 1961 to $35 \%$ in 2001. The NEA survey also found that $43 \%$ of men versus $36 \%$ of women teachers cited low salary as a factor that would cause them to leave the teaching profession before retirement. It is clear that we also need to improve the status of the teaching profession so that it attracts the same overall diversity that we see in our student populations.

\section{Large-Scale Factors in Science Education Reform}

\section{State-Level Policy and Science Education}

Geoscience education advocates have been forced to closely monitor the activities of state-level educational policy makers to prevent the elimination of K-12 ESS standards. For example, in 1998, ESS standards were removed by the Texas State Board of Education and, as a consequence, Earth sciences classes did not meet state graduation requirements (Roy, 2002). In 1985, the state of North Carolina decided to take Earth science out of 8th grade classrooms and administrators did not plan to move it to another grade level (Watson and Tucci, 2002). It was only through the efforts of individuals and advocate groups that 13 years later, in 1998, the state board of education made Earth and environmental science a graduation requirement. In contrast, in New York State the state-level Board of Regents has historically offered Earth science as one of the core science assessments for graduation. As a result, $67 \%$ of 9 th grade students in New York take ESS (AGI, 2002), nearly ten times the national average.

\section{Curricular Change}

The issues of K-12 geoscience education cannot be considered separately from the challenge of bringing about institutional changes, such as science education reform in schools. Cuban (1992) reviewed 100 years of curriculum stability and change in American schools and found that there are two categories of contributing factors, internal and external. In this case, external factors would be organizations such as the American Geological Institute, the National Science Foundation, and the U.S. Department of Education. Internal factors include school administrators, science departments, teachers, students, and parents.

In the 1960s and 1970s the external geoscience community was successful in influencing change and promoting Earth science curricula in schools. These highly funded, well-coordinated efforts by the American Geological Institute and National Science Foundation engaged teachers in exciting new scientific discoveries through professional development and the creation of new curricula. Despite these efforts, the status and position of ESS is still not equal to that of biology, chemistry, or physics.

However, difficulty in bringing about change is not limited to the geosciences. For example, in the 1970s when other NSF-funded science curriculum projects were investigated, researchers found that "the methods the teachers used and the topics they chose to teach to students were largely unaffected by federal curriculum efforts ... that inquiry methods, central to many of the curricular materials ... seldom ap- 
peared in the classrooms they observed" (Cuban, 1992, p. 227). Cuban's research underscores the need for the geoscience education community to undertake more studies of the enacted curriculum, professional development, and outreach programs to better understand how geoscience is being taught and to identify effective instruction that reflect the National Science Education Standards (NRC, 1996).

\section{Stereotyped Science}

The stereotypical view of Earth and space courses is that they are less rigorous than biology, chemistry, and physics. This phenomenon further supports and reinforces misconceptions about the breadth, depth, and rigor of the geosciences. Consequently, an interesting investigation of the status of geoscience education would be to analyze the perceptions of students, parents, teachers, and administrators of the field and its educational value. Once we understand the nature of participants' perceptions we can better configure plans of action.

\section{Geoscience Education Research Foci}

Geoscience education reform has a nearly exclusive focus on developing more engaging geology lessons (e.g., curriculum that connects to local environments, using visualizations). The majority of scholarly articles in geoscience education, in particular the articles from the Journal of Geoscience Education, have investigated classroom interactions and the effects of using different instructional techniques, identifying student misconceptions, and developing lessons to affect conceptual change. An exception to this has been the work of Semken and coworkers who have investigated sense of place (Semken, 2005; Semken \& Butler Freeman, 2008).

An examination of the subject index of the Journal of Geoscience Education indicates that the main focus of the journal has been on science content with only 2 of the 71 subject areas directly addressing teacher education or pre-college education. While a focus on teaching content is important and necessary work, it does not directly address K-12 geoscience education, undergraduate recruitment problems, and the lack of well-prepared secondary Earth science teachers. Nor does it have the broad theoretical framework that allows for considering policy, systemic change, or access and equity issues.

\section{A Sociocultural Perspective}

We know what the big problems are in geoscience education, but if we want to understand why they exist, and persist, we need to ask new questions and use additional theoretical lenses. If we want more students to major in the geosciences, and also have some of them become secondary science teachers, we need to understand why there has been such a dramatic decline in undergraduate majors and determine what can be done to reverse this trend.

There are many useful perspectives that science education researchers have at their disposal to study these issues, and have been skillfully used in studying other science contexts. Lemke (2001) carefully delineated many ways that researchers can benefit from using sociocultural theories and perspectives to view science education issues, design investigations, and provide insights into diverse phenomena. These views acknowledge the complexities of teaching and learning science and a myriad ways to study it. Research in geoscience education can benefit from adding sociocultural research perspectives and theories about fundamental concepts such as identity and self-concept to the theoretical frameworks currently used.

As an example, we look to Martin, Milne, and Scantlebury (2006), who studied strategies to help college science professors enact more equitable teaching structures in their classrooms. These researchers used cultural sociology as a theoretical framework and found that "structure and agency exist in a dialectical relationship so that classroom structures impact the agency of each teacher and teacher agency can change classroom structures" (p. 823). In their suggestions for reforming instructional practices Martin et al., recommend that teachers use strategies that allow all students to participate equally, rather than only those who dominate discussions and receive a larger portion of teacher's attention.

\section{Culture and Science}

One area we believe would be fruitful to investigate is the cultural gap between students' everyday lives and identities and the culture of geoscience. Maddock (1981) described science education as a cul- 
tural enterprise and Cobern and Aikenhead (1998) have documented that there are cultural aspects to learning science. Both the sociological view of "socializing students into a community of practitioners" and the anthropological view of "enculturation via a rite of passage into behaving according to [scientific] cultural norms and conventions" (Cobern \& Aikenhead, 1998, p. 39) provide us with different views of teaching and learning science that go beyond individual cognition.

A good example of programmatic research in science education using sociological and anthropological perspectives is the work of Lee (2001) and Lee and Luykx (2007), who have done critical work in equity, diversity, and science education around issues of students' culture and language. Within geoscience education research, Riggs and Semken (2001) provide us with a case study of co-developing geoscience curricula at Dine College on the Navajo Nation that honors traditional ways of making meaning and engaging students with culturally sensitive pedagogies. In another study, Riggs, Robbins, and Darner (2007) have used a sociocultural perspective to explore the issue of participation of under represented groups by examining the challenges of recruiting Native American students into the geosciences.

A sociocultural perspective provides us with a conceptual framework to investigate why we may be failing to recruit geoscience majors and future teachers from underrepresented groups. The research in science education points to cultural differences, fear of assimilation, and our own failure to provide students with the mechanisms to ease "border crossings" (Pomeroy, 1994). However, it is necessary to investigate the many specific contexts in which geoscience education occurs and how these cultural differences are made manifest.

\section{Science as a Social Language}

Other sociocultural researchers examine society as an interacting group of discourses, and science, in turn, as marked by social language (Gee, 2005; Halliday, 2004; Lemke, 1990). In this view, Western science has its own form of discourse, one that can be foreign and daunting for many students because it often asks those students to adopt ways of speaking and communicating without valuing the identities and discursive patterns they already possess. Brown's (2006) study of 9th and 10th graders' language, identity, and appropriating science discourse gives us some interesting insights into students' learning in and of science. Brown's results indicated that "students experienced relative ease in appropriating the epistemic and cultural behaviors of science, whereas they expressed a great deal of difficulty in appropriating the discursive practices of science" (p. 96). This is an important distinction for science teachers and researchers to investigate further, one which geoscience educators could apply to their own classroom contexts. Indeed, without access to the discourses of science classrooms, students will fail to demonstrate their knowledge or find academic success.

\section{Science Identities}

Gee (2001) describes how we can use identity as an analytic lens for research in education. He also argues that for young people, adopting an academic identity of any kind, in this case as a science learner, requires relinquishing their own identities (Gee, 2004). For many adolescents and young adults this is not seen as desirable and/or viable and ultimately they reject further participation and enculturation into the practices and norms of doing science.

Using the notion of an academic identity, Carlone and Johnson (2007) developed a model of science identity based on their research about the undergraduate, graduate, and career science experiences of 15 successful women of color. Their study clarified theoretical conceptions of a person's science identity and encourages us to reconsider how we go about recruitment and retention in science. By seeking to include the ways women of color experience, make meaning of, and negotiate the culture of science, these researchers provide us with a productive approach to investigate science identity. However, because none of their study participants were geoscientists, we recommend that researchers use Carlone and Johnson's science identity model to see if there are similar findings in the geosciences.

In another study of underrepresented students, Brown (2004) examined the intrapersonal conflict created by participation in the culture of high school science. He used discourse analysis of videotaped science classroom activities, lectures, and laboratories and identified four different discursive identities: Opposition status, Maintenance status, Incorporation status, and Proficiency Status. Brown concluded that 
students who exhibited Opposition status avoided the use of science discourse. These categories of identities may also be useful in observing students' interactions with the geosciences.

\section{Equity and Science Education Research}

Gender Equity. Research on attitudes of school-aged girls toward science by Baker and Leary (1995) revealed that girls think women can and should do science, regardless of topic or area. However, parents can negatively affect a girl's desire to pursue science as a career if they hold traditional gender stereotypes. Pedagogical strategies also matter, as girls generally prefer learning science in interactive and social contexts rather than through isolating activities, such as note-taking and lectures. Consequently, if geoscience teachers and faculty were to broaden their teaching practices to include more peer interaction they would be more likely to meet the needs of female learners. By increasing the appeal of geoscience classes to more students, in particular to those not already enculturated, undergraduate departments may be able to recruit and retain more students. However, this has yet to be investigated systematically and we should not assume that this is the only solution. Lifestyle decisions and family obligations also contribute to the attrition of women from the pool of females in the sciences, including the geosciences.

Libarkin and Kurdziel (2003) have also summarized issues of gender and careers in the geosciences from the research in science education. They reported declining numbers of women in the geosciences from participation as undergraduates to becoming geoscience faculty members. Building on this work, a fruitful area for researchers may be to investigate what kinds of actions have, or have not, been taken to support women's work in the geosciences and what kinds of changes could broaden their participation.

Socioeconomic Status and Science Education. Students in high-poverty urban schools present a challenge to science educators. Basu and Barton (2007) found that three conditions must be met in order for students in high-poverty urban schools to develop an interest in science. First, science experiences must be connected to the students' visions of their futures. Second, the learning environment must support valued social relationships. And third, science activities must create a sense of agency for students and reinforce students' perceptions of the purpose of science.

In another study of low-income urban middle school students and teachers, Barton and Tan (2009) used a design experiment to shift teaching practices to be more supportive of students' everyday knowledge and practices as they learned about food and nutrition. Using qualitative data and grounded theory, the researchers found that allowing students to use their everyday knowledge enhanced the learning experience, contributed to the development of a learning community, and promoted student achievement.

A succinct description of the state of urban science education can be found in Fraser-Abder, Atwater, and Lee's (2006) editorial for the special issue of JRST on urban science education. They provided a research agenda and a summary of influential factors in urban science achievement that merit further investigation by all science educators, including geosciences educators. The factors they considered most important were science student identity, science teacher identity, and school science policy. Fraser-Abder et al. stress that "science achievement gaps should be interpreted within the context of ideological and methodological limitations" (p. 601), this includes race/ethnicity, culture, language, social class, and gender. Their framework provides another useful lens for examining underrepresentation in the geosciences and geoscience education.

\section{A Proposed Research Agenda for Geoscience Education}

\section{Using Multiple and Mixed Research Methods}

Embarking on a new phase of geoscience education research calls for adopting research approaches that incorporate multiple perspectives. Multi-method and mixed methods (Greene, 2007) approaches using complementary theoretical lenses for investigating geoscience education phenomena hold the promise of enhancing geoscience education research and advancing scientific literacy. For example, Wood, Lawrenz, Huffman, and Schultz (2006) used four theoretical constructs, three unique sets of empirical factors and seven experiential themes that describe the middle school environment in their study of school-level variables tied to student achievement. This approach provided them with multiple perspectives on the 
same issue, revealing that students, teachers, and principals held very different perceptions of their school environment, views not necessarily revealed with a single method or theory.

\section{Asking New Questions}

A new phase of geoscience research also calls for new questions that address enrollment issues, the number of individuals choosing to become geoscience teachers, and students' identities and preferred ways of meaning-making and learning. In addition, we need to better understand students' agency and how it affects their views of science and consideration of the geosciences as a career path. We need to further explore the status of women and underrepresented groups in the geosciences and how that status affects engagement and persistence in pursuing a science career. We must carefully examine the discipline for differences in the quantity and quality of mentoring and opportunities for students to engage in geoscience. Further, we must ask whether geoscience practitioners have multiple ways of communicating that appeal to the diverse cultural values and norms of students.

Action Research in Higher Education. The attitudes of geoscience faculty toward K-12 education, and students' whose career goals are teaching and education, rather than scientific research, are areas that would benefit from action research. For example, action research was fruitful in understanding women's experiences in a GK-12 STEM program, and what they needed from their graduate programs (Buck, LesliePelecky, Lu, Clark, \& Creswell, 2006). Action research has also identified factors that influence students' decisions to enroll in chemistry (Dalgety, Coll, \& Jones, 2003) by investigating the role of teaching on students' attitudes toward chemistry, chemistry self-efficacy, and learning experiences.

Since the negative effects of teacher-centered instruction on undergraduates is well documented (Walczyk, Ramsey, \& Zha, 2007), it is particularly important that we identify the attitudes of geoscience faculty toward progressive, inquiry-based instructional practices (Yerrick \& Roth, 2005) and their willingness to change instructional practices. Geoscience faculty should also engage in self-study about student perceptions of their departments and what departmental attitudes are toward teaching and K-12 education.

Collaborating with colleagues in education could help to evaluate pedagogical practices in geoscience courses and lead to professional development activities that could broaden teaching skills. Research instruments like Walczyk et al.'s (2007) on-line survey used with science and math college faculty could provide productive starting points with the purpose of revealing geoscience faculty's attitudes toward teaching science. In addition to improving students' learning and motivation, research on faculty attitudes toward teaching could also lead to better mentoring, which, in turn, may improve recruitment and retention.

\section{Conclusion}

In this editorial we have described the problems facing the geoscience community. We have proposed theoretical lenses, research methods, and research questions for geoscience education research. We encourage science education researchers to collaborate with one another, and in particular with geoscience faculty, as a researched-informed way to improve scientific literacy worldwide in the geosciences.

\section{References}

American Association for the Advancement of Science (1993). Benchmarks for Scientific Literacy: Project 2061. New York, NY: Oxford University Press.

American Geological Institute (2002). National Status Report on K-12 Earth Science Education, April 2002.

Baker, D., \& Leary, R. (1995). Letting girls speak out about science. Journal of Research in Science Teaching, 32(1), 3-27.

Barstow D., \& Geary, E. (Eds.) (2002). Blueprint for Change: Report from the National Conference on the Revolution in Earth and Space Science Education. Cambridge, MA: TERC. Online http://www.EarthScienceEdRevolution.org

Barton, A. C., \& Tan, E. (2009). Funds of knowledge and discourses and hybrid space. Journal of Research in Science Teaching, 46(1), 50-73.

Basu, S., \& Barton, A. C. (2007). Developing a sustained interest in science among urban minority youth. Journal of Research in Science Teaching, 44(3), 466-489. 
Britner, S. L. (2008). Motivation in high school science students - A Comparison of gender differences in life, physical, and Earth science classes. Journal of Research in Science Teaching, 45(8), 955-970.

Blank, R., Langesen, D. (eds.) (2005). State indicators of science and mathematics education. Washington, DC: Council of Chief State School Officers.

Brown, B. A. (2006). "It isn't no slang that can be said about this stuff": Language, identity, and appropriating science discourse. Journal of Research in Science Teaching, 43(1), 96-126.

Brown, B. A. (2004). Discursive identity: Assimilation into the culture of science and its implications for minority students. Journal of Research in Science Teaching, 41(8), 810-834.

Buck, G. A., Leslie-Pelecky, D. L., Lu, Y., Clark, V.L.P., \& Creswell, J. W. (2006). Self-definition of women experiencing a nontraditional graduate fellowship program. Journal of Research in Science Teaching, 43(8), 852-873.

Carlone, H. B., \& Johnson, A. (2007). Understanding the science experiences of successful women of color: Science identity as an analytic lens. Journal of Research in Science Teaching, 44(8), 1187-1218.

Cobern, W. W., \& Aikenhead, G. S. (1998). Cultural aspects of learning science. In: Fraser, B. J. \& Tobin, K. G. (eds.), International Handbook of Science Education (pp. 39-52). Boston: Kluwer Academic.

Cuban, L. (1992). Curriculum stability and change. In: Jackson, P. W. (ed.), Handbook of Research on Curriculum (pp. 216-247). New York: Macmillan Publishing Company.

Dalgety, J., Coll, R. K., \& Jones, A. (2003). Development of chemistry attitudes and experiences Questionnaire (CAEQ). Journal of Research in Science Teaching, 40(7), 649-668.

Dodick, J., \& Orion, N. (2003). Geology as an historical science: Its perception within science and the educational system. Science and Education, 12(2), 197-211.

Fraser-Abder, P., Atwater, M., \& Lee, O. (2006). Research in urban science education: An essential journey. Journal of Research in Science Teaching, 43(7), 599-606.

Gee, J. P. (2005). Introduction to discourse analysis (2nd ed.). London: Routledge.

Gee, J. P. (2004). Situated language and learning: A critique of traditional schooling. New York: Routledge.

Gee, J. P. (2001). Identity as an analytic lens for research in education. Review of Research in Education, 25, 99-125.

Greene, J. (2007). Mixed methods in social inquiry. San Francisco: John Wiley \& Sons, Inc.

Halliday, M.A.K. (2004). The language of science. London: Continuum.

Horizon Research, Inc. (2002a). 2000 National Survey of Science and Mathematics Education: Status of High School Biology Teaching. http://www.horzon-research.com

Horizon Research, Inc. (2002b). 2000 National Survey of Science and Mathematics Education: Status of Secondary School Earth Science Teaching. http://www.horzon-research.com

Huntoon, J. E., \& Lane, M. J. (2007). Diversity in the geosciences and successful strategies for increasing diversity. Journal of Geoscience Education, 55(6), 447-457.

Lee, O. (2001). Culture and language in science education: What do we know and what do we need to know? Journal of Research in Science Teaching, 38(5), 499-501.

Lee, O., \& Luykx, A. (2007). Science education and student diversity: Race/ethnicity, language, culture, and socioeconomic status. In: S. Abell \& N. Lederman (eds.), Handbook of Research on Science Education. Mahwah, NJ: Lawrence Erlbaum Associates, Inc., 171-198.

Lemke, J. L. (2001). Articulating communities: Sociocultural perspectives on science education. Journal of Research in Science Teaching, 38(3), 296-316.

Lemke, J. L. (1990). Talking science: Language, learning, and values. Norwood, NJ: Ablex Publishing.

Lewis, E. B. (2008). Content is not enough: A history of secondary earth science teacher preparation with recommendations for today. Journal of Geoscience Education, 56(5), 445-455.

Libarkin, J. C., \& Kurdziel, J. P. (2003). Gender and the geosciences. Journal of Geoscience Education, 51(4), 446- 452.

Maddock, M. N. (1981). Science education: An anthropological viewpoint. Studies in Science Education, 8, 1-26.

Martin, S. N., Milne, C., \& Scantlebury, K. (2006). Eye-rollers, risk-takers, and turn sharks: Target students in a professional science education program. Journal of Research in Science Teaching, 43(8), 819-851.

Mayer V. J. (ed.), (2002). Global science literacy. Dordrecht, The Netherlands: Kluwer Academic Publications.

National Education Association. (2003). Status of the American School Teacher 2000-2001. Washington, DC: National Education Association. http://www.nea.org

National Research Council. (1996). National science education standards. Washington, DC: National Academy of Science.

National Science Foundation, Division of Science Resources Statistics. (2007). Women, minorities, and persons with disabilities in science and engineering. Arlington, VA: NSF. Available at http://www.nsf.gov/statistics/wmpd 
National Assessment of Educational Progress. (2000). U.S. Department of Education. Washington, DC: National Assessment of Educational Progress. http://nces.ed.gov

Pomeroy, D. (1994). Science education and cultural diversity: Mapping the field. Studies of Science Education, 24, 49-73.

Ridky, R. (2002). Why we need a corps of earth science educators. Geotimes, 47(9), 16-19.

Riggs, E. M., Robbins, E., \& Darner, R. (2007). Sharing the land: Attracting native American students to the geosciences. Journal of Geoscience Education, 55(6), 478-485.

Riggs, E. M., \& Semken, S. (2001). Culture \& science: Earth science education for native Americans. Geotimes, 46, 14-16.

Romey, W. D. (1966). A strategy for alleviating the shortage of earth science teachers. Journal of Geological Education, 14(3), 89-90.

Roy, E. C. (2002). Earth science in Texas: A progress report. Geotimes, 47(9), 24-25.

Semken, S. (2005). Sense of place and place-based geosciences teaching for American Indian and Alaska native undergraduates. Journal of Geoscience Education, 53, 149-151.

Semken, S., \& Butler Freeman, C. (2008). Sense of place in the practice and assessment of place-based science teaching. Science Education, 92(2), 1042-1057.

Walczyk, J. J., Ramsey, L. L., \& Zha, P. (2007). Obstacles to instructional innovation according to college science and mathematics faculty. Journal of Research in Science Teaching, 44(1), 85-106.

Watson, M. E., \& Tucci, W. (2002). A victory for earth science: How a group of determined people made earth science a graduation requirement in North Carolina. Geotimes, 47(9), 20-22.

Wood, N. B., Lawrenz, F., Huffman, D., \& Schultz, M. (2006). Viewing the school environment through multiple lenses: In search of school-level variables tied to student achievement. Journal of Research in Science Teaching, 43(3), 237-254.

Yerrick, R. K., \& Roth. W-.M. (eds.) (2005). Establishing scientific classroom discourse communities: Multiple voices of teaching and learning research. New Jersey: Lawrence Erlbaum Associates, Publishers. 